\title{
Evaluation of effective parameters on fabrication of BSA nanoparticles
}

\author{
Mostafa Rahimnejad, Ghasem Najafpour* and Mohsen Jahanshahi \\ Nano and Biotechnology Research Lab., School of Chemical Engineering, Noshirvani University \\ of Technology, Babol, Iran.
}

\footnotetext{
* Corresponding author: najafpour@nit.ac.ir, najafpour8@yahoo.com, Fax: +98-1113234204

Mailing Address: Faculty of Chemical Engineering, Noshirvani University of Technology, Babol, Iran. Postcode: 4714871167
} 


\begin{abstract}
Coacervation technique was implemented in fabrication of BSA nanoparticle for the purpose of drug delivery system. Nanoparticle was purified with 48,800 g centrifuge, and then followed by dialysis, micro and ultra filtration. The fabricated nanoparticles were subjected to physical, morphological and biochemical characterization. The analyzed samples by SEM and AFM proved the semi-spherically shape of the particles whilst the size distribution was measured by photon correlation spectroscopy. Fourier transforms infra-red spectroscopy (FTIR) spectrum indicated that the fabricated nanoparticles were pure. The impact of various parameters upon the particle size was extensively investigated. The concentration of glutaraldehyde at fixed temperature had absolutely no significant effect on the size of particles. The affecting parameter was modeled to predict the size of nanoparticle. At low temperature $\left(4^{\circ} \mathrm{C}\right)$, the nanoparticle size of $89.3 \mathrm{~nm}$ was fabricated with pure BSA concentration of $20 \mathrm{mg} \cdot \mathrm{ml}^{-1}$.
\end{abstract}

Keywords: Bovine serum albumin, nanoparticles, pure protein, coacervation, nanosphere, semispherical particle 


\section{Introduction}

Over the past few decades, there has been considerable interest in developing biodegradable nanoparticle (liposome, virus like particle (VLP), protein and etc.) as effective drug delivery devices ${ }^{1,2,3,4}$. Nanoparticles of biodegradable polymers are sustainable and well controlled for targeted drug delivery. This method may improve the therapeutic effects and reduce the side effects of the formulated drugs ${ }^{5,6}$. An important advantage associated with the use of nanoparticles includes the ease of preparation from well-understood biodegradable polymers and high stability in biological fluids and long duration for storage ${ }^{7,8}$. Nanoparticles size is defined as particle size of well below $1000 \mathrm{~nm}$. When the drug is encapsulated by the nanoparticle, the product is known as nanocapsulated particle. If the medicine is uniformly coated on the exterior of the nanoparticle then, it is called nanosphere. Schematic diagram of nanocapsulated and nanosphere particles loaded with drug are shown in Figure 1.

The carrier itself should be non-toxic and biodegradable so that it does not accumulate indefinitely in tissues ${ }^{9}$. Also, the biodegradable nano- and microparticles are stated to be very useful delivery devices for various active agents ${ }^{10}$. Albumin nanoparticles have extensively been investigated as appropriate drug delivery system because of their biodegradable property, nontoxic and non antigenic ${ }^{11,12}$. The particles are defined in primary structure and contained high amount of charged amino acids (i.e. lysine). The albumin-based nanoparticles could allow the electrostatic adsorption of positively or negatively charged molecules without the requirements of any other compounds. In addition, protein nanoparticles can easily be prepared by coacervation or controlled desolvation processes ${ }^{13,14}$. Several methods have been developed for the preparation of albumin nanoparticles, such as emulsification, coacervation or desolvation. 
Emulsification method is used by means of an aqueous albumin solution is emulsified in an oily phase and subsequently precipitated by heat treatment. This technique usually leads to formation of microparticles ${ }^{16,17}$. Recently, nanoparticles fabrications by coacervation methods are reported $^{11,16}$. A desolving agent (e.g. a salt solution, alcohol, and acetone) was added to an aqueous Bovine Serum Albumin (BSA) solution in order to dehydrate the gelatin molecules. That is resulted in change in conformation of stretched to coiled, which is indicated by turbidity in the aqueous phase. Then, a cross-linking agent is added to harden the native particles ${ }^{18,19,20}$. The preparation conditions for colloidal drug carrier nanoparticles should be controlled in order to have particle size of less than $200 \mathrm{~nm}^{13}$.

The purpose of present research paper was to fabricate nanoparticles in a unique range which is suitable for the drug delivery system. The effect of manufacturing conditions such as $\mathrm{pH}$, BSA concentration, agitation speed, rate of additional organic solvent was extensively investigated. The characteristics of the fabricated protein nanoparticles were modeled and the affect of the influential parameters on particle size were discussed.

\section{Materials and Methods}

\subsection{Materials}

Bovine serum albumin (BSA) (fraction V, with purity of 98\%), Tween-20, ethanolamine and glutaraldehyde, $25 \%$ solution, were commercially supplied by Sigma Aldrich. Analytical grade and high purity of sodium azide and all other chemicals were supplied from Merck (Germany).

\subsection{Preparation of BSA Nanoparticles}


Coacervation technique was implemented for preparation of BSA nanoparticles [19]. Anhydrous ethyl alcohol was added to $150 \mathrm{ml}$ BSA $(5 \mathrm{mg} / \mathrm{l}$ in $10 \mathrm{mM}$ Tris $/ \mathrm{HCl}$ contained $0.02 \%$ sodium azide, $\mathrm{pH}$ 7.5) till the solution became turbid, then $150 \mu \mathrm{l}$ of $25 \%$ glutaraldehyde was added for cross linking. The reaction was continued at room temperature $\left(24^{\circ} \mathrm{C}\right)$. Ethanolamine was added to block the non-reacted aldehyde functional group. Also Tween-20 was added at a final concentration of $0.01 \% \mathrm{v} / \mathrm{v}$ to stabilize the preparation. Large aggregates were eliminated by centrifuge $\left(50,000 \mathrm{~g}, 30 \mathrm{~min}, 4^{\circ} \mathrm{C}\right)$. The supernatant was dialyzed and subsequently micro and ultra filtrated through an acetate membrane and polyvinylchloride copolymer membrane with cut off of $0.2 \mu \mathrm{m}$ and $300 \mathrm{kDa}$, respectively. The concentration of BSA determined with Coomassie Blue reagent ${ }^{21}$. The size distribution and shape of BSA nanoparticles were determined by scanning electronic microscope $(\mathrm{SEM})^{22}$.

\subsection{Determination of Nanoparticle Size and Distribution}

The size distribution of the prepared BSA nanoparticle was analyzed by photon correlation spectroscopy (PCS). PCS is industrially preferred method for sub-micron particle size analysis. The sample analyzed in PCS device should consist of well dispersed particles in liquid medium. In the specified condition, the particles possess in constant random motion, which is refer to Brownian motion using Einstein-diffusion equation stated below:

$$
D=\frac{\delta^{2}}{2 T}=\frac{R T}{6 \pi \eta \mathrm{rN}_{\mathrm{A}}}
$$

PCS measures the speed of this motion by passing laser beam. Equation (1) is used in PCS for projection of the particle size. As a result of Brownian motion, particles migrate an average 
distance $(\delta)$ in a short time interval (T). The diameter of the particles can be determined from the Einstein-diffusion equation where $\mathrm{D}$ is the diffusion coefficient, $\mathrm{N}_{\mathrm{A}}$ is Avogadro's number, and $\mathrm{R}$ is the gas constant and $\mathrm{T}$ absolute temperature. PCS determined the average particle size and Polydispersity Index (PI) which is the measurement for the range of particle sizes within the measured sample particles. This index is dimensionless, that is the average molecular weight of all nanoparticles to a number of particles that is in the range of 0.05 to 0.7 . Generally, this index is always less than 0.7 .

\subsection{Morphology}

The morphologies of the BSA nanoparticles were observed by Atomic Force Microscope (AFM) and Scanning Electron Microscope (SEM). The sample was examined under AFM using Philips model class 11 Laser productions; Netherland, at 600-700nm wave length. Surface profiles were generated from AFM, raw data by the SISCANPRO software (vs. 1.3, Surface Imaging Systems).

To take the image with scanning electron microscopy (SEM), fifty microlitres of the nanoparticle preparation were freeze dried (EMITECH; Model IK750, Cambridge, UK) on a polished aluminum surface. After drying, the sample was sputtered with gold for 30s under Polaron machine (BAL-TEC, Model SCDOOS, Switzerland). Afterwards, SEM was performed with a Stereoscan S360 Brand SEM-Leica (Cambridge, UK) with the upper detector at $15 \mathrm{kV}$. The magnification was set at 65,000 .

\subsection{Determination of Particle Purity}


The purity of BSA nanoparticles was investigated by Fourier Transform Infra-Red (FTIR) Spectroscopy (Perkin Elemer Instruments, UK). The samples for FTIR analysis were prepared by grinding $99 \% \mathrm{KBr}$ with $1 \%$ nanoparticles and then pressing the mixture into a transparent tablet. Phasmatophotometer was employed and Fourier nanoparticle samples were scanned at IR range of $450-5000 \mathrm{~cm}^{-1}$. Detector has to be purged by clean dry helium gas (He) to amplify the signal level and reduce the moisture.

\section{Results and Discussion:}

\subsection{Particle size and distribution}

Wide range of protein (BSA) nanoparticles having unique particles size and anionic characters to other nanoparticles such as adenovirus and plasmid DNA were fabricated. Based on size distribution, average particle size was measured by PCS. The average diameter and polydispersity of all samples in several batches were analyzed at room temperature with a scattering angle of $90^{\circ}$. The size of nanoparticle which is dominant and has the maximum percentage in the suspension introduced as a mean size. Figure 2 exhibits the suspension of BSA nanoparticle size analyzed by PCS. The mean size was $226.2 \mathrm{~nm}$ and polydispersity Index was 0.117. The low value of PI showed that the samples had very well dispersity of the particles (less than 0.7 ). The values obtained for all of the fabricated nanoparticles were below 0.7 ; that means all of the prepared samples were quite well dispersed and uniformed.

\subsection{Physical Characterization of Nanoparticles}

For determination of the nanoparticles properties (morphology and purity), the samples were randomly taken and the reported data were in triplicates. AFM technique has been widely 
applied to provide surface and morphological information in nanoscale. Figure 3 depicts the images of the shape and the surface characteristic of the nanoparticles were successfully obtained by Atomic Force Microscopy (AFM). It was shown that the fabricated nanoparticles were almost having a smooth surface. Along with these characteristics, BSA nanoparticles proposed to be a suitable candidate for loading drugs on/in the nanoparticles. Two and three dimensional images of BSA nanoparticle are shown in Figure $3 \mathrm{a}$ and $\mathrm{b}$. The outer surface of the sample particle was analyzed by AFM. The sample was prepared in the solution at $\mathrm{pH}$ of 7.5 , temperature $24^{\circ} \mathrm{C}$, concentration of $15 \mathrm{mg} \cdot \mathrm{ml}^{-1}$ and 200rpm.

Figure 4 shows the SEM image of the outer surface of the nanoparticles. The SEM images show the morphology of particle surface and size distribution of the fabricated nanoparticles. It was clear that most of the morphologies of the fabricated protein nanoparticles were semispheres with diameter in the range of 60 to $300 \mathrm{~nm}$. Monograms were obtained from AFM and SEM image. The resulted nanoparticles were uniformly distributed. The smooth surfaces of the fabricated particles are shown with magnification of 14588.

\subsection{Purity of the BSA nanoparticles}

Figure 5 shows the Fourier transform infra-red (FTIR) spectroscopy of pure BSA, nanoparticles comprised of BSA without purification and purified BSA nanoparticles. FTIR analysis was used for determining the purity of the fabricated nanoparticle. The sample was prepared and analyzed at the general condition ( $\mathrm{pH}$ value of 7 , temperature $24^{\circ} \mathrm{C}, \mathrm{BSA}$ concentration $5 \mathrm{mg} \cdot \mathrm{ml}^{-1}$ and 200 rpm agitation). The base for comparison is the standard BSA with the pure and impure BSA samples. It is clear from the FTIR spectrum that at the specific range of 4000 to nearly $1500 \mathrm{~cm}^{-1}$ wavelength, the purification of BSA nanoparticles was well accomplished. Also, the molecular 
structure of the resulted BSA nanoparticle was characterized by gel electrophoresis SDS-PAGE and results were published elsewhere ${ }^{23}$.

\subsection{Analysis of the Fabricated Nanoparticles}

Figure 6 presents the linear model fitted with the experimental data for the size of fabricated particles with respected to agitation rate in the range of 200 to $700 \mathrm{rpm}$, at 4,14 and $24^{\circ} \mathrm{C}$. The model is fairly fitted with the experimental data and the slope of the lines increased as the temperature increased. However at high agitation rate, the size of particle was decreased. At low temperature, the agitation rate was insignificant with respect to fabricated nanoparticle size, but the size of the particle was increased as the temperature increased.

The effects of addition of desolvation agent on the size of nanoparticles were investigated with respect ethanol flow rate of $0.5,1,1.5$ and $2 \mathrm{ml} \mathrm{min}^{-1}$ and temperature range of 4 to $24^{\circ} \mathrm{C}$ at fixed BSA concentration. Figure 7 depicts, the rate of ethanol addition had no significant effect on size of the prepared nanoparticles. However as the temperature increased, the size of nanoparticles were increased which was independent of ethanol flow rate.

The effect of $\mathrm{pH}$ on size of nanoparticles is shown in Figure 8. The size of nanoparticle was maximized at $\mathrm{pH}$ value of 6 . The size of nanoparticle at acidic and alkaline conditions was reduced. Generally, proteins are sensitive to $\mathrm{pH}$, their activities are dependent on $\mathrm{pH}$. The effect of $\mathrm{pH}$ on size of nanoparticles with respect to temperature $\left(4,14\right.$ and $\left.24^{\circ} \mathrm{C}\right)$ was examined. The highest nanoparticle diameter was observed at $\mathrm{pH}$ value around the isoelectric point. At the 
isoelectric $\mathrm{pH}$ value the fabricated nanoparticles became unstable and average particle diameter increased up to 163,204 and 214 nanometer at 4,14 and $24{ }^{\circ} \mathrm{C}$, respectively.

In preparation of nanoparticle cross linking are particularly useful for delivering the macrosolutes and may serve as drug therapeutic agents ${ }^{8}$. Effects of glutaraldehyde concentrations in nanoparticle fabrication as cross linking agents were investigated. The particles were fabricated with various amounts of the cross linking agent. The fabricated nanoparticles were cross linked by glutaraldehyde after the desolvation agent (coacervation method).

Figure 9 presents the effect of glutaraldehyde concentration on size of the fabricated nanoparticles at 4,14 and $24^{\circ} \mathrm{C}$. It is obvious to observe that increasing temperature had no significant effect on nanoparticle size, but the amount of cross linking agent was not observed to be influential in the resulted particles diameter from PCS. The dash lines show the fitted data as linear model.

In contrast to the poor influence of the glutaraldehyde concentration and the rate of ethanol addition, the BSA concentration in the solution before addition of desolvation agent, which was strongly influenced on diameter of the nanoparticle (Figure 10) The effect of BSA concentration $\left(5,10,15,20\right.$ and $\left.30 \mathrm{mg} \cdot \mathrm{l}^{-1}\right)$ on size of particles diameter at three different temperatures was discussed. As the temperature increased, the size of nanoparticles was increased. However at high concentration of BSA, the size was gradually decreased. The obtained experimental data were perfectly fitted with the projected linear model. This research indicated that the fabricated BSA nanoparticle by coacervation technique with average size has good ability for drug delivery 
system because of the nanoparticles diameter below 100nm are often used for drug delivery systems $^{24}$. The fabricated BSA nanoparticles were below $100 \mathrm{~nm}$. This option is very important for drug delivery systems. It has been reported that the nanoparticles have very good intracellular uptake when the nanoparticle diameter was decreased ${ }^{25,26}$.

\section{Conclusion}

BSA nanoparticles were fabricated with predictable and reproducible size of less than $200 \mathrm{~nm}$; by coacervation procedure. The size of nanoparticle obtained at $4^{\circ} \mathrm{C}$ drastically lower than the other temperature (minimum size of particle was $89.3 \mathrm{~nm}$ at $20 \mathrm{mg} \cdot \mathrm{ml}^{-1}$ concentration of BSA). AFM and SEM analysis from different samples indicated that the fabricated nanoparticles were nanosphere and semi spherical shape. Optimization studies for the fabrication of nanoparticulate in aspect of recovery of nanoparticle from the initial solution was excluded and subjected to future research.

\section{References}

1. Barat, A., Crane, M. \& Ruskin H. J. Quantitative multi-agent models for simulating protein release from PLGA bioerodible nano- and microspheres. J. Pharm \& Biomed Analysis. 48, 361-368 (2008).

2. Jung, K. O., Drumright, R., Siegwart, D. J. \& Matyjaszewski, K. The development of microgels/nanogels for drug delivery applications, Prog. Polym. Sci. 33, 448 - 477 (2008) .

3. Kumaresh, S. et al. Biodegradable polymeric nanoparticles as drug delivery devices. J Control Rel . 70, 1-20 (2001).

4. Jahanshahi, M., Williams, S., Lyddiatt, A. \& Shojaosadati, S. A. Preparation and purification of synthetic protein nanoparticulates. IEE Proc-Nano-biotechnol. 151, 176-182 (2004).

5. Couvreur, P., Gref, R., Andrieux, K. \& Malvy, C. Nanotechnologies for drug delivery: Application to cancer and autoimmune diseases. Prog in Solid State Chem. 34, 231-235 (2006). 
6. Rahimnejad, M., Jahanshahi, M. \& Najafpour, G. D. Production of Biological Nanoparticles from Bovine Serum Albumin for Drug Delivery. African J Biotechnol . 5, 1918-1923 (2006).

7. Mua, L. \& Seowc, P. H. Application of TPGS in polymeric nanoparticulate drug delivery system. Colloids and Surfaces B: Biointerfaces . 47, 90-97 (2006).

8. Quan, G. \& Wang, T. Chitosan nanoparticle as protein delivery carrier-Systematic examination of fabrication conditions for efficient loading and release. Colloids and Surfaces B: Biointerfaces .59, 24-34 (2007).

9. Jahanshahi, M., Aghajani, H. \& Ling, T. C. Assembly \&purification of nanostructure bioproducts: protein nanoparticle characterization and non-stick exterior coating adsorbents. Int J Nano Sci \& Nanotechnol. 1, 9-20 (2005).

10. Feczko, T., Toth, J. \& Gyenis, J. Comparison of the preparation of PLGA-BSA nano- and microparticles by PVA, poloxamer and PVP. Colloids and Surfaces A: Physicochem. Eng. Aspects . 319, 188-195 (2008).

11. Weber, C., Coester, C., Kreuter, J. \& Langer, K. Desolvation process and surface characterization of protein nanoparticles. Int J Pharm. 194, 91-102 (2000).

12. Muller, B., Leuenberger, H. \& Kissel, T. Albumin nanospheres as carriers for passive drug targeting: an optimized manufacturing technique. Pharm Research. 13, 32- 37 (1996).

13. Arnedo, A., Espuelas, S. \& Irache, J. M. Albumin nanoparticle as carriers for a phosphodiester oligonucleotide. Int J Pharm. 244, 59-72 (2004).

14. Bikash, K. J. \& Raj, C. R. Optical sensing of biomedically important polyionic drugs using nano-sized gold particle. Biosen and Bioelectronics. 23, 1285-1290 (2008).

15. Soppimath, K. S., Aminabhavi, T. M., Kulkarni, A. R. \& Rudzinski, W. Biodegradable polymeric nanoparticles as drug delivery devise. J of Controlled Release . 70, 1-20 (2001).

16. Langer, K., Balthasar, S., Vogel, V., Dinauer, N., Briesen, H. \& Schubert, D. Optimization of the preparation process for human serum albumin (HSA) nanoparticle. Int. J. Pharm. 257, 169-180 (2003).

17. Mohanty, B. \& Bohidar, H. B. Systematic of alcohol-induced simple coacervation in aqueous gelatin solutions. Biomarcromol . 4, 1080-1086 (2003).

18. Sungwon, K. et al .Minimalism in fabrication of self-organized nanogels holdingboth anticancer drug and targeting moiety. Colloids and Surfaces B: Biointerfaces . 63, 55-63 (2008). 
19. Lazko, J., Popineau, Y. \& Legrand, J. Soy glycine microcapsules by simple coacervation method. Colloids and Surface B: Biointerfaces.37, 1-8 (2004).

20. Sui, Z. J., King, W. J. \& Murphy, W. L. Protein-based hydrogels with tunable dynamic responses. Adv Func Mater. 18, 1824-1831(2008).

21. Bradford, M. M. A rapid and sensitive method for quantitation of microgram quantities of protein utilising the principle of protein dye-binding. An Biochem . 72, 248-254 (1967).

22. Zhang, Z., Burton, S., Williams, S. \& Liddiat, A. Design and assembly of solid-phase for the effective recovery of nanoparticulate, bio product in fluidized bed contactors, Biosep. 10, 113-132 (2001).

23. Jahanshahi, M., Najafpour, G. D., Rahimnejad, M. Applying the Taguchi method for optimized fabrication of bovine serum albumin (BSA) nanoparticles as drug delivery vehicles. African J Biotechnol . 7, 362-367 (2008).

24. Jayanth, P., Vinod, L. B iodegradable nanoparticles for drug and gene delivery to cells and tissue, Adv Drug Delivery Reviews. 55, 329-347 (2003).

25. Desai, M. P., Labhasetwar, V., Walter, E., Levy, R. J. \& Amidon, G. L. The mechanism of uptake of biodegradable micro particles in Caco-2 cells is size dependent, Pharm. Res.14, 1568-1573 (1997).

26. Liu, Z., Jiao, Y., Wang, Y., Zhou, C. \& Zhang, Z. Polysaccharides-based nanoparticles as drug delivery systems, Adv Drug Delivery Reviews. 60, 1650- 1662 (2008). 

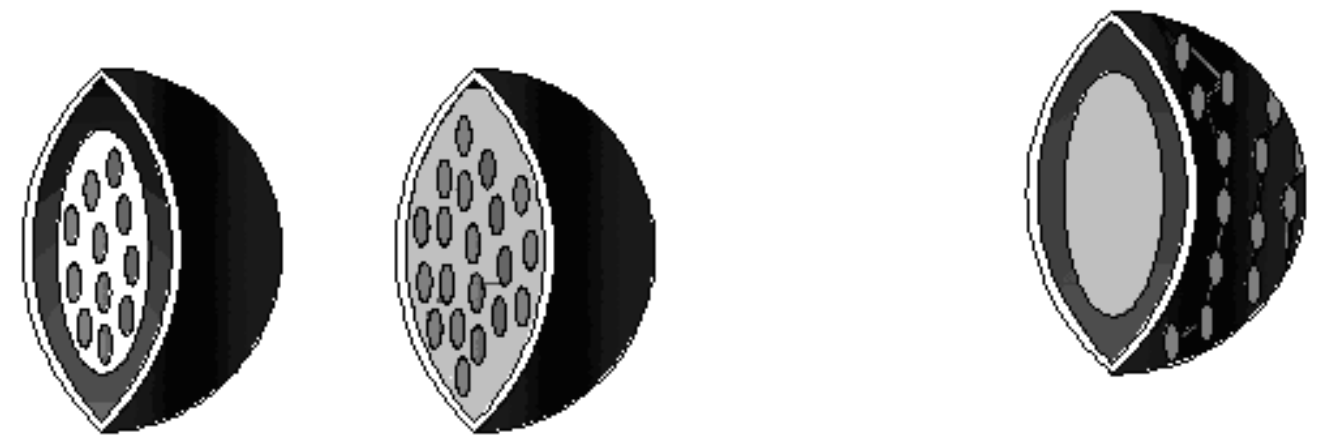
a: Entrapped drug
b: Surface adsorbed drug

Figure 1| Schematic diagram of the encapsulated and coated nanoparticle for the drug delivery system.

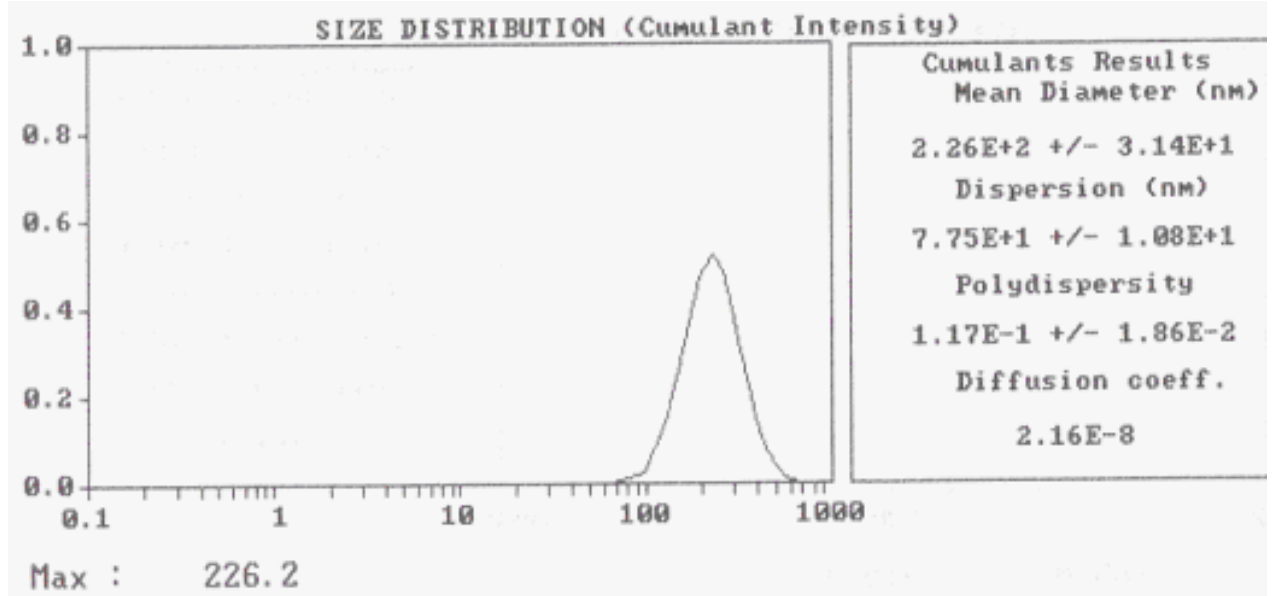

Figure 2| Photon correlation spectroscopy of the BSA nanoparticles 


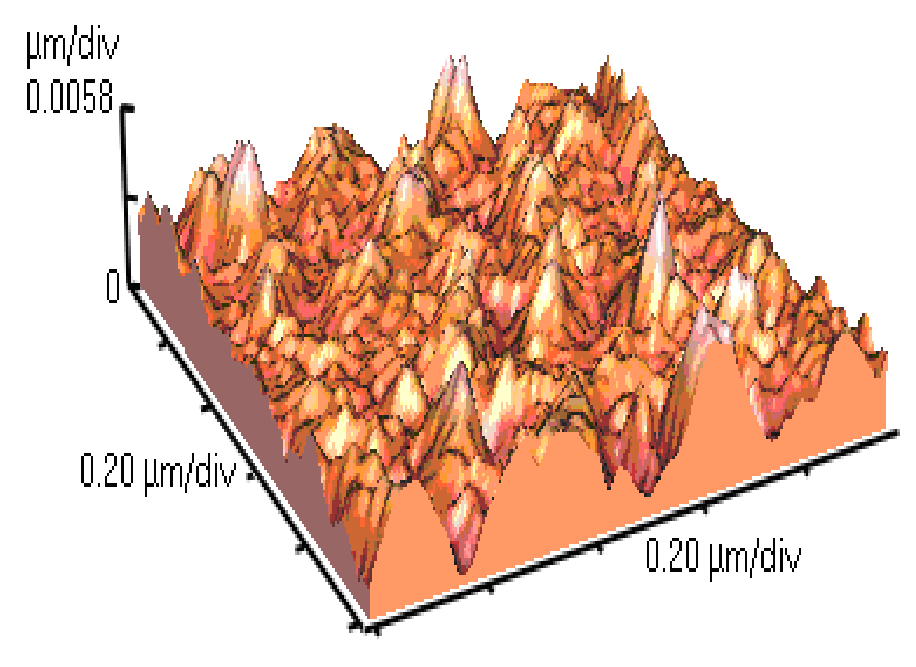

a: Three dimensional image of the outer surface for dilute solution

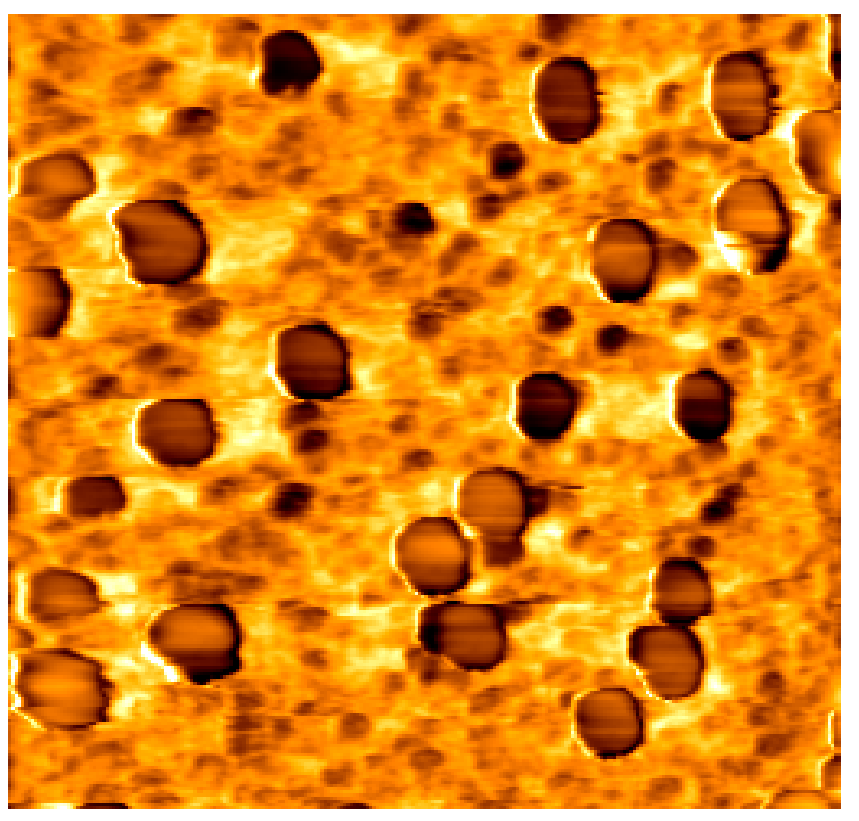

b: Two dimensional image of the outer surface for dilute solution

Figure 3| Atomic force microscopy of the outer surface of the BSA nanoparticles 


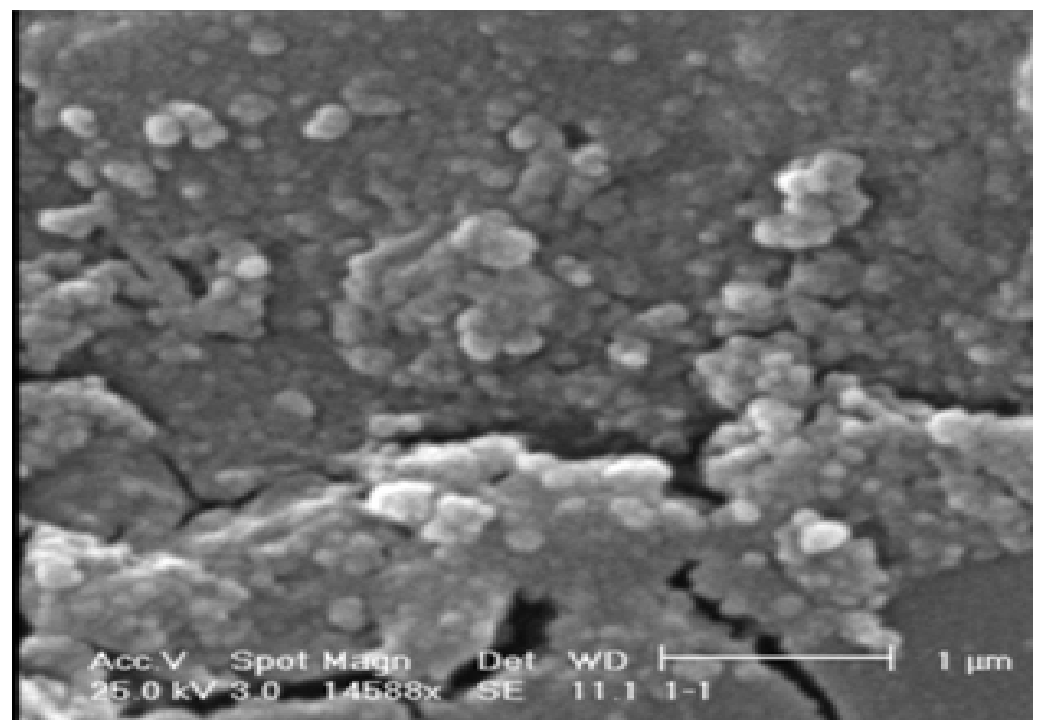

Figure 4| Scanning electronic microscopy of the outer surface of the BSA Nanoparticles

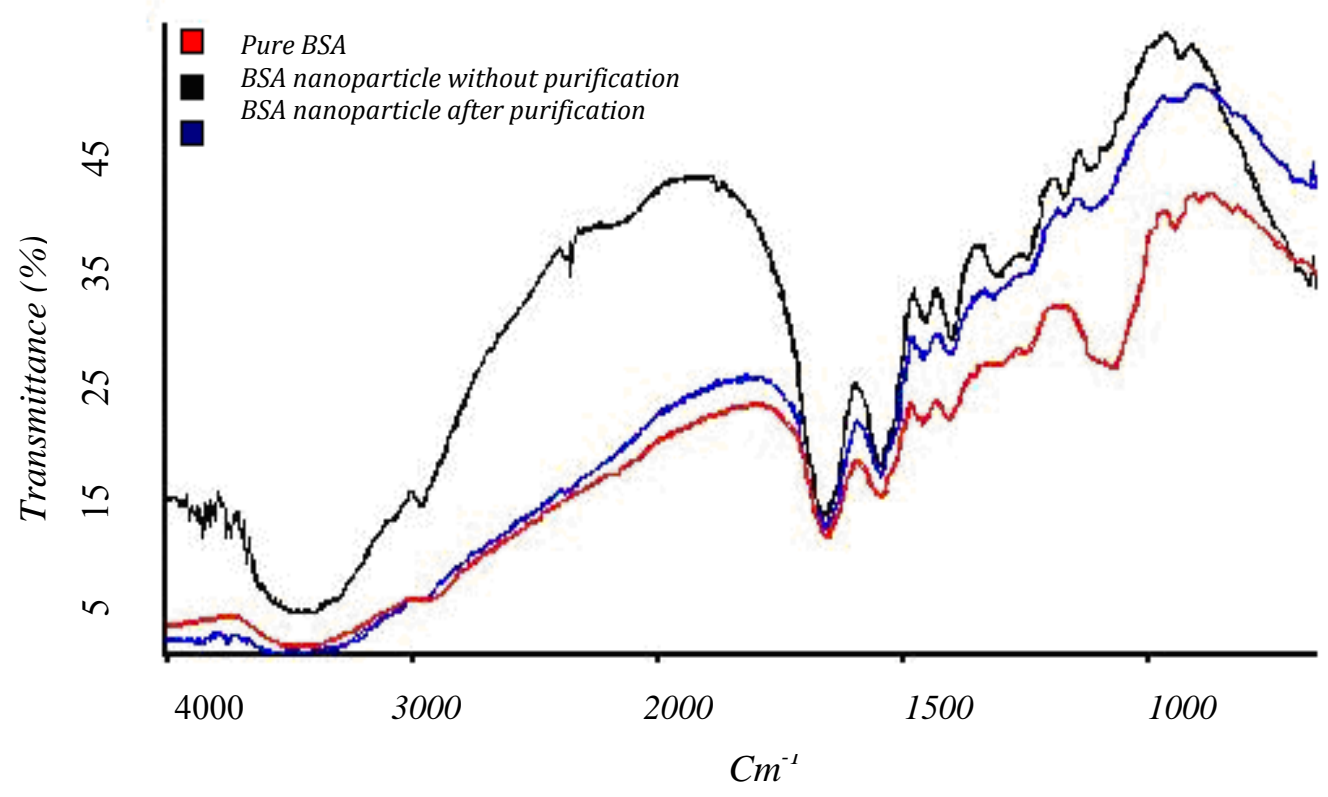

Figure 5| FTIR analysis of BSA nanoparticle 


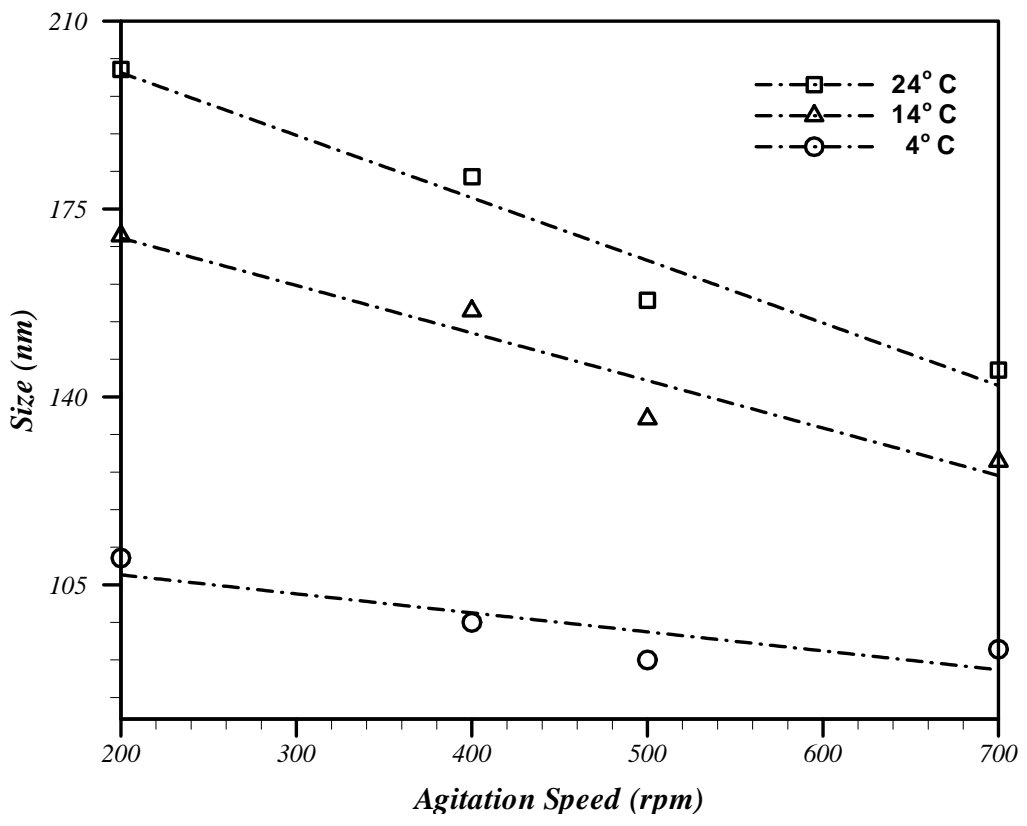

Figure 6| The effect of agitation speed on the particle size

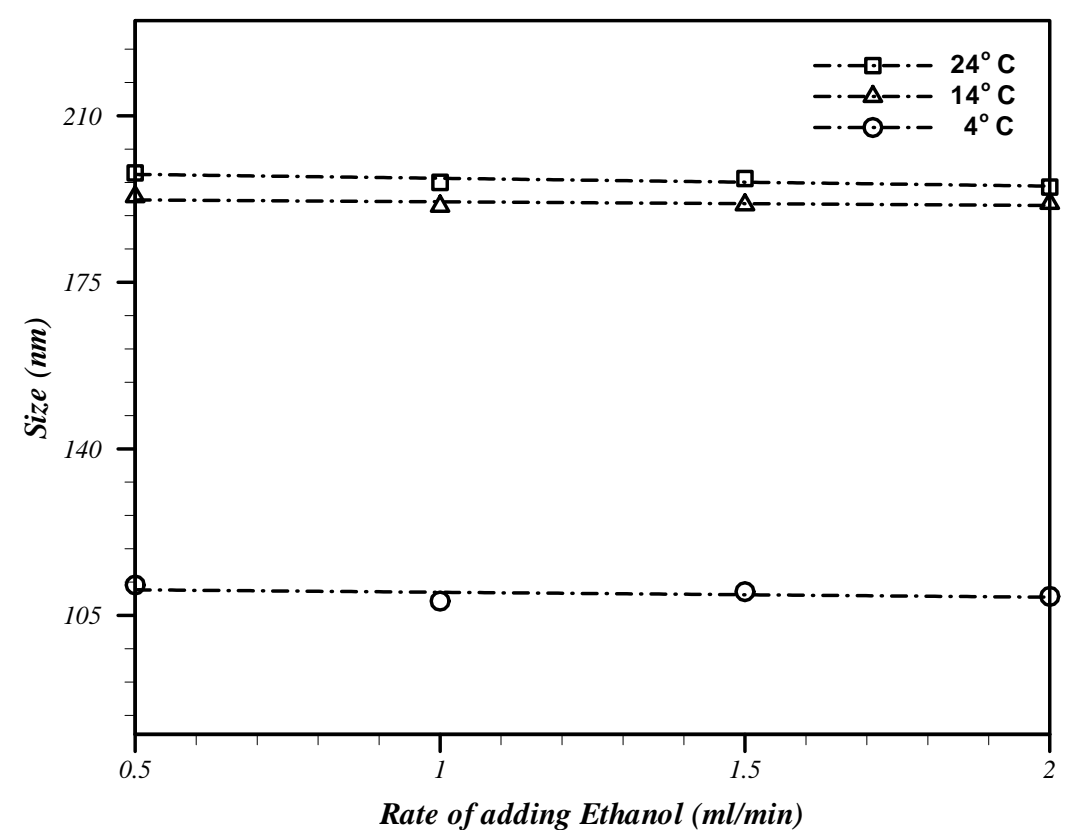

Figure 7 | The effect of rate of addition of Ethanol $\left(\mathrm{ml} \cdot \mathrm{min}^{-1}\right)$ on the particle size 


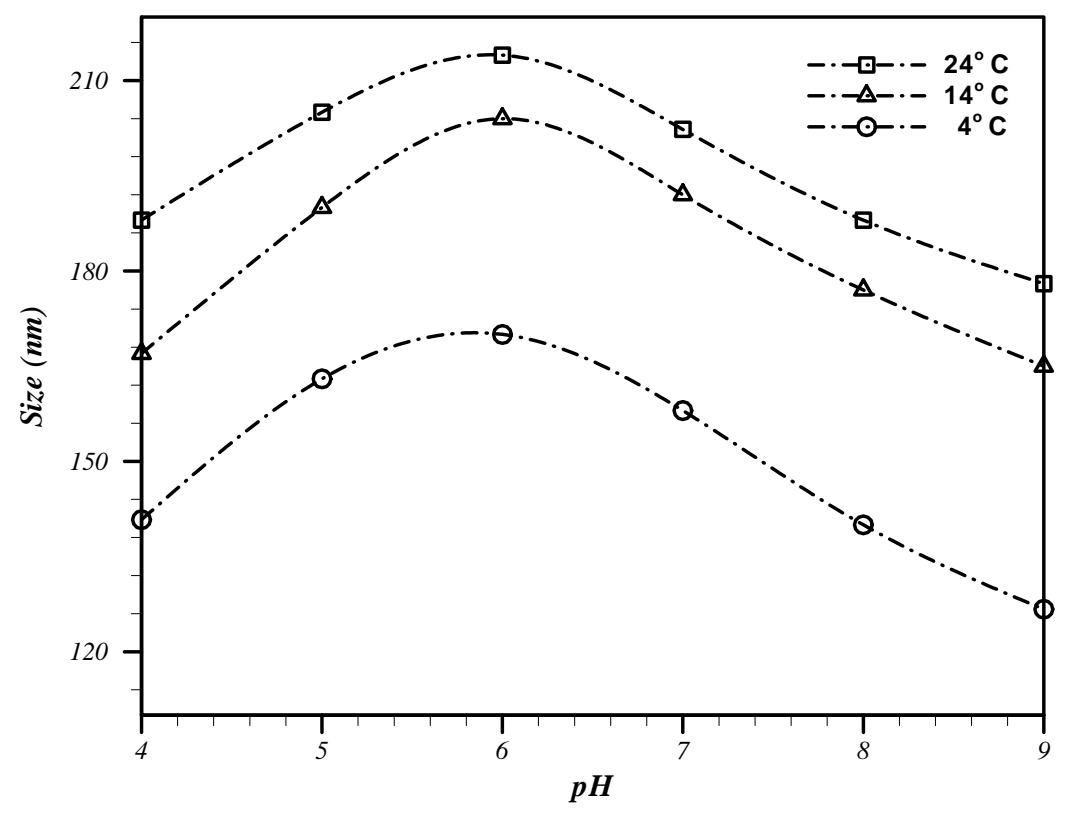

Figure 8| The effect of $\mathrm{pH}$ on the average size of particles.

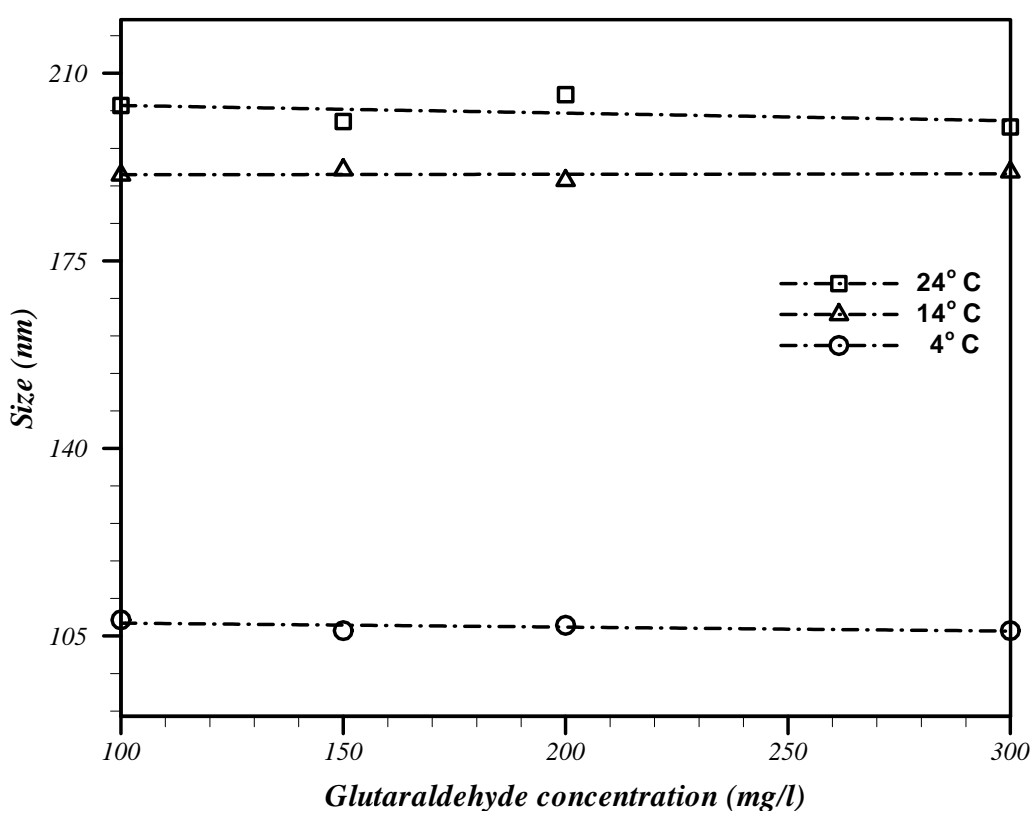

Figure 9| The effect of glutaraldehyde concentration on the particle size 


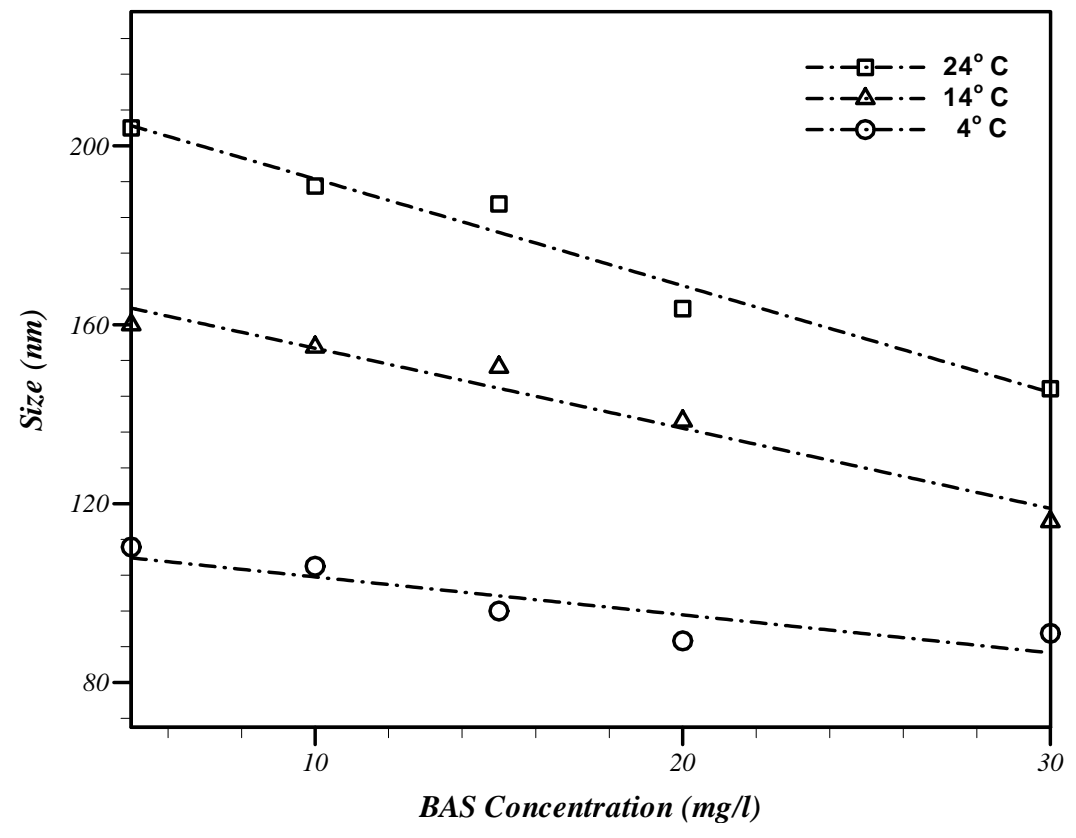

Figure 10| The effect of BSA concentration on the particle size 